\title{
॥EL QUE SE METE CON MI BARRIO ME CAE MAL II ALTERNATIVAS ANALÍTICAS A LA ESTANDARIZACIÓN EN MÚSICA POPULAR
}

\section{IWHOEVER MESSES WITH MY NEIGHBORHOOD DOES NOT LIKE ME॥ ALTERNATIVES TO STANDARDIZATION IN POPULAR MUSIC ANALYSIS}

\begin{abstract}
Martín Eckmeyer
martineckmeyer@gmail.com Instituto de Investigación en Producción y Enseñanza del Arte Argentino y Latinoamericano. Facultad de Bellas Artes. Universidad Nacional de La Plata / Facultad de Humanidades, Artes y Ciencias Sociales. Universidad Autónoma de Entre Ríos. Argentina
\end{abstract}

Recibido: 12/12/2017 | Aceptado: 23/3/2018

\section{RESUMEN}

Aunque Theodor Adorno no es responsable de la dicotomía musicológica que separa una auténtica música del pueblo de los supuestos fetiches con que la industria coloniza la subjetividad colectiva, sus trabajos sobre música popular contribuyeron mucho a fortalecerla argumentalmente. Este trabajo ensaya una refutación utilizando los medios del propio Adorno: el análisis de la materialidad musical. Apelaremos a un componente deliberadamente ausente en su obra: la transculturación de las músicas afroamericanas.

\section{PALABRAS CLAVE}

Música popular; transculturación; análisis musical

\section{ABSTRACT}

Although the musicological split between an authentic music of the folk and the fetishes used by industry to colonize collective subjectivities was not created by Theodor Adorno, his writtings about popular music strengthened its arguments a lot. This paper essays a refutation through Adorno's own means: the analysis of music materiality. I will take into account one aspect deliberately left apart in his work: transculturation of Afro-American music.

\section{KEYWORDS}

Popular music; transculturation; music analysis

1 Estrofa que marca el clímax, y con la cual se inicia el soneo, de la canción «La Perla» (2008) de Calle 13, Rubén Blades y La Chilinga. 
«Mozart o Bach reflejan el sueño de armonía de la burguesía mejor y antes que toda la teoría política del siglo XIX.» Jaques Attali (2011)

Entre los textos sobre música de Theodor W. Adorno existen unos pocos -aunque importantes- que se ocupan específicamente de la música popular. Los más conocidos son Sobre el carácter fetichisto de la música y lo regresión de lo escucho [1938] (2009) y lo concerniente al mercado musical que se aborda en Dialéctica de la Ilustración: Fragmentos de filosofía [1944] (2001), escrito junto con Max Horkheimer, particularmente, en el capítulo sobre la industria cultural, que se concibe en términos de «lluminismo como mistificación de masas». Existe, también, un texto más específico, 2 Sobre lo música popular (2002), escrito en inglés en 1941 junto con George simpson. Centraremos nuestro análisis en este último y tomaremos algunos pasajes de los otros para completar el cuadro.

Como se sabe, Adorno es profundamente crítico hacia la música popular, la cual asocia - sin excepción- con los mecanismos de dominación y opresión de las masas que despliega la industria cultural. Estas posiciones, habitualmente tildadas de prejuiciosas y elitistas (Leach, 2015), han sido refutadas en términos de significación cultural y social de la música popular (Frith, 2014; Middleton, 1990; Negus, 1997) y hasta se ha intentado cuestionar el enfoque de Adorno haciéndole probar su propia medicina, sometiendo sus textos a un enfoque crítico según la dialéctica negativa (Paddison, 1982). Hasta donde sabemos solo en un texto muy reciente (Stone, 2017) se ha intentado refutar a Adorno de acuerdo a lo que él desarrolla como estrategia de análisis: buscar en la propia materialidad de la música popular rasgos que permitan cuestionar su interpretación como elementos represivos, inauténticos y afirmativos per se. Intentaremos hacer esto a partir de la materialidad de algunas músicas populares latinoamericanas, específicamente, de aquellas que exhiben su condición transcultural.

De manera simultánea, vincularemos este análisis con la concepción capitalista de la música y su historiografía, que propondremos en estrecha relación con la música tonal-funcional del canon culto occidental. Consideramos importante realizar este intento, no tanto para refutar al propio Adorno, del cual están claros su etnocentrismo y su apología de la cultura germanófila, sino porque las derivaciones de sus ideas habitan hoy los ámbitos de producción académica a tal punto que, al rechazarlas, obstaculizan el desarrollo de enfoques socio-históricos sobre la música en general y, más aún, sobre la música popular (Moore, 2008). Esto es fácilmente cotejable en la baja frecuencia que tales estudios y enfoques

2 Además del texto referido, Adorno escribió sobre música popular en Sobre la situación social de la música [1932] (2015) y en Sobre el Jazz [1936] (2018). 
tienen todavía en comparación con otros campos y disciplinas. Como un trauma de la infancia, las ideas de Adorno se nos aparecen constantemente, y más si pretendemos negar su existencia. Todavía hay que elaborar el síntomo Adorno para ampliar el análisis de la música popular.

\section{ESTANDARIZACIÓN Y COMPRESIÓN DE LA MÚSICA POPULAR}

«Mientras la cultura popular es siempre una realidad verificable, la cultura oficial resulta con demasiada frecuencia en nuestros países un simple proyecto ideológico.» Adolfo Colombres (2007)

Para empezar, Adorno [1941] (2002) considera que las diferencias en el campo de la música deben buscarse mediante términos más precisos y desprejuiciados que los habituales «culto y popular, alto y bajo» (p. 167). Para él, la diferencia última radica en discriminar aquellas músicas críticas de las ocríticos. Adorno buscará en las condiciones materiales, en la organización sonora, los rasgos definitorios que asocien a la música popular a lo segundo (Paddison, 1982), y que, de esta manera, la tornen irremediablemente falsa e inauténtica, en contraste con la música serio. Para fundamentar esta diferenciación, el autor utilizará el concepto de estondarizoción, marca constitutiva de la música popular que vuelve a todas sus manifestaciones abstractas, vacías, intercambiables y predecibles.

Por consiguiente, para el autor de Fráncfort, en la música culta todos los elementos poseen una identidad que, al mismo tiempo que es propia, está estrechamente vinculada con la organización total de la obra. En la música popular, en cambio, la organización precede a la música porque está estandarizada y, por lo tanto, los detalles no son sino ocurrencias en la superficie de una estructura abstracta y vacía de contenido que no pueden modificar ni conmover. Los elementos sonoros en la música popular, por muy aventurados que se presenten, no son más que «un disfraz o adorno detrás del cual siempre puede percibirse el esquema» (Adorno, [1941] 2002, p. 168). Y la forma más patente en que esta condición se revela es en la ausencia de conflicto entre el todo y la parte, ya que "la estandarización abarca desde los rasgos más generales hasta los más específicos» (Adorno, [1941] 2002, p. 164).

Desde esta perspectiva, la autenticidad en música, la verdad, solo puede revelarse a través del detalle individual y la explicitación de su relación alienada en función del todo. Esto ocurre, según Adorno, únicamente en la música culta, en cuyas obras los detalles jamás se integran estéticamente en la totalidad, sino que se mantienen ajenos a la reconciliación «haciendo que la alienación y el temor sean ahora parte integrante de la misma 
estructura»³ (Paddison, 1982, p. 205). En cambio, en la música popular, el detalle se integra de modo consensual a la estructura, ocultando su alienación y, de esta manera, produce el engaño. Por tal motivo, en la música popular «el oyente, ante lo complicado solo oye lo simple» (Adorno, [1941] 2002, p. 168). Y aquí viene la relación con el orden social: «si los momentos parciales ya no ejercen un sentido crítico respecto de ese todo predeterminado, suspenden la crítica que la totalidad estética congruente ejerce sobre los aspectos quebradizos de la sociedad» (Adorno, [1938] 2009, p. 18).

En los análisis de Adorno existe notablemente una jerarquía entre los dominios del lenguaje musical, de modo tal que los asuntos relativos a la armonía, la melodía y la forma son los centrales, es decir, los que hacen a la estructura, mientras que lo tímbrico, lo textural y lo rítmico se asocian con este carácter alienado que la música popular perpetúa por ocultamiento. Esto lleva a que se piensen las estructuras de la música popular como eminentemente sencillas y repetitivas, moldes de nulo valor que son recubiertas con la sensualidad de las cadencias, el grano de la voz o los pasajes improvisados de los solos instrumentales. Queda claro que lo que para Adorno es musicalmente relevante coincide con la tradición tonal occidental. No por casualidad Arnold Schönberg dedicó buena parte de su tiempo a compilar esta tradición, además de decretar la ineptitud musical de Cage en base a su carencia de todo sentido de lo armonía. Más allá del etnocentrismo, el problema de esto es que aquello que en la música popular es lo relevante y generador de sentido, para Adorno son detolles, un ropaje dispuesto sobre una estructura, tal cual podría haberlo concebido un orquestador del siglo XVIII. Y todavía más, son estos «detalles de estimulación sensual» los que se transforman en fetiches perdiendo todo sentido (Adorno, [1938] 2009, p. 24).

Esta condición material es específica de la música popular. Para Adorno, si la música clásica deviene inauténtica es a consecuencia del accionar de la industria cultural que genera la fetichización de la obra y la regresión en su escucha. La falta de oposición al reflejo pasivo de las tendencias estructurantes de la sociedad - condición de la autenticidad de la música «verdadera» (Paddison, 1982, p. 207) - no está tanto en los materiales de la música culta capturada por el amusement, sino en su secuestro mediante el proceso de trasposición del arte a la esfera de consumo que mejora la calidad de las mercancías «hasta terminar en una síntesis de Beethoven con el Casino de París» (Adorno \& Horkheimer, [1944] 2001, p. 179). Es decir que, salvo la línea vienesa que va de Mozart a Schönberg, la música culta se vuelve clásica al entregarse al consumo a cambio de sacrificar su contenido crítico. Pero que se convierta en un ámbito de fetiches es asunto de la contemporaneidad, no de su carácter material intrínseco.

3 «So that alienation and fear are now part of the structure of art itself» (Paddison, 1982, p. 205). Traducción del autor del artículo. 
Sin embargo, la vinculación de la música culta entre los sectores de poder político y económico se hace evidente mediante el análisis histórico que permite comprender que desde al menos el siglo XVII, sino antes, el compositor de los grandes nombres de la historia de la música es una pieza constitutiva de la maquinaria simbólica necesaria para afirmar la legitimidad de los sectores hegemónicos. La música tonal del canon al que Adorno rinde homenaje puede entenderse, también, como mecanismo para hacer creer en la consensualidad del orden de la sociedad.

La transformación de la música popular en valor de cambio es históricamente consecuencia a posteriori de la mercantilización de la música culta: si la reclusión de la performance popular en un local se hace en el siglo XIX con fines comerciales para sacarla de la calle y regular su comercialización (Attali, 2011), esto obedece al mecanismo fundamentalmente comercial desarrollado para la ópera en 1637 y para el concierto público en 1672. Si a comienzos del siglo XVII ya existe un mercado para las canciones y las tonadas que se venden como pliegos sueltos en las calles (Frith, 2006), es gracias al mecanismo de la imprenta musical, desarrollado durante el XVI para la comercialización de motetes, misas y madrigales, es decir, música de la élite dominante. Incluso con el advenimiento de la grabación lo primero que producirán las compañías fonográficas en el siglo XX son fundamentalmente selecciones de arias y fragmentos de sinfonías. ${ }^{4}$ Cuando como derivación -y no al revés - del mercado de las vedettes de concierto se genera la vedette popular (Attali, 2011), la música popular será comprimida con el objeto de clasificarla y de manipularla en el mercado capitalista mediante las categorías que el positivismo genera para reafirmar en términos conceptuales la transformación en mercancía de la música culta: la obra, el estilo, el aparato analítico armonicocéntrico.

La teoría sobre la música es concomitante con el mercado y la industria cultural. Domestica a la música popular a través de las categorías, los nombres, las teorías y los dispositivos de la música culta, transformándola en obra-objeto (comercial) y explicando su génesis según el personalismo, que deposita en el individuo la razón de la marcha histórica. Si tomamos como analogía los procesos de eliminación de picos dinámicos en la grabación de audio, podemos decir que lo que aquí ocurre es una compresión de tipo conceptual.

En donde sin dudas este proceso resulta más evidente es en la condena del ritmo en la música popular. Más adelante veremos que existe una estrecha relación con lo corporal que explica este ensañamiento. Pero detengámonos aquí en cómo Adorno relaciona explícitamente el ritmo de la música popular con un sentido opresivo que genera como resultado un

4 Para un panorama sensiblemente distinto de los comienzos de la industria fonográfica en nuestro país y la región, se sugiere consultar la reseña de Lautaro Casa y Sabina Maza sobre el libro de Marina Cañardo Fóbricas de Música. Comienzos de la Industrio Discográfica en la Argentina (1919-1930) (2018, pp. 159-161) que integra la presente edición de Clang. 
deseo de obedecer. Los medios de la música popular son entendidos, así, como intrínsecamente represivos.

Este tipo obediente es el tipo rítmico [...]. Cualquier experiencia musical de este tipo está basada en la unidad temporal de fondo de la música; en su «pulsación». Para esta gente, tocar rítmicamente significa tocar de modo que [...] se conserva la relación con el metro de base. Para ellos, ser musical significa ser capaz de seguir modelos rítmicos dados [...]. Esta es la manera en que su respuesta a la música expresa de forma inmediata su deseo de obedecer (Adorno, [1941] 2002, p. 189).

Aunque tácitamente Adorno utiliza como modelo vivo al jazz, es decir, la música afronorteamericana, en ella es donde encuentra esta alienación rítmica disciplinadora, que no permite, al rechazar la negación, oponerse a la situación tal cual es. Es de todas formas significativo que Adorno encuentre que esta gente no retiene, en su música, «la tensión necesaria entre sujeto y objeto, individuo y colectivo» (Paddison, 1982, p. 207). Para intentar contrastar esto y determinar si los desarrollos musicales afrodescendientes reproducen o cuestionan el orden establecido, analizaremos un caso de lo que Ángel Quintero Rivera (2009) Ilama las bailables músicas mulatos. Una música que por añadidura elegimos deliberadamente comercial, vinculada al stor system y que, además, hace gala de un aspecto que refuerza lo que según Adorno es el engaño de la música popular: la explicitación de la rebeldía y la oposición al sistema social.

La canción que nos servirá de ejemplo es «La Perla» (2008), del grupo puertorriqueño Calle 13 y el cantante panameño Rubén Blades, a los cuales se une en la performance el grupo argentino de percusión La Chilinga. Puede pensarse que esta canción reúne elementos de modalidades más tradicionales de las músicas caribeñas, como el son y la salsa, junto con otros vinculados al rap en español, más contemporáneo y por ello menos referenciado con la región, aunque no por eso menos afrodescendiente. Estos rasgos se escuchan inmediatamente desde el comienzo, ya que la canción comienza con un patrón rítmico muy típico [Figura 1].

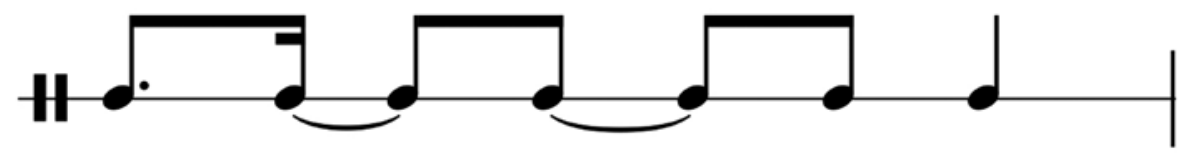

Figura 1. Patrón rítmico o clove a partir de lo cual se organiza el ritmo en «La Perla» 
En la academia, este esquema suele ser explicado como ritmo aditivo 0 superposición métrica, que indican, en el primer caso, un exotismo y, en el segundo, una convivencia entre lo ternario y lo binario. Nosotros preferimos la denominación del citado Quintero Rivera quien recupera el término de uso entre los músicos populares: la clove. Para este autor, las músicas mulatas «simultáneamente son y no son occidente» (Quintero Rivera, 2009, p. 69) y el concepto de clave está claramente del lado del no son. A diferencia de la organización métrica occidental, basada en la división proporcional de la unidad y la regularidad acentual -estondarizoción si las hay-, las claves afrodescendientes conforman unidades de duración irregular y, de esta manera, diseminan los acentos de acuerdo a conformaciones de tiempo variables y heterogéneas, tanto en lo sucesivo como en lo simultáneo. No es un flujo narrativo, sino la sucesión de unidades discretas y diversas, en dimensión y en sentido: cuantos rítmicos, si se permite la analogía con la física.

Como vemos, la organización de las claves no responde en absoluto al concepto de métrica. Y mal haríamos en aplicarlo, ya que solo sirve para comprimir el sentido rítmico de estas músicas: el compás o metro occidental es una estructura predeterminada, abstracta, organizada en un rígido esquema jerárquico ontes de que los sonidos lo pueblen. Cuando nos referimos al ritmo según la métrica, los detolles que revelan escapando a la predeterminación son integrados y neutralizados porque se los entiende como síncopas o hemiolas: desvíos. Para que estos existan debe aceptarse la existencia de una norma, y esta es siempre abstracta y preexistente al fenómeno musical. He aquí, en la música culta occidental y su ritmo objetivado en torno al compás, la verdadera estandarización, producida en los mismos y exactos términos referidos por Adorno.

También vemos cómo funciona la compresión conceptual de la música popular, al desplegar el aparato analítico generado en occidente para producir y para explicar la música culta. Esto es lo que hace Adorno al considerar al ritmo de la música popular una mera repetición y predeterminación, subestima y desoye su carácter dinámico, heteróclito, expresión musical de una realidad habitada por la heterogeneidad de las diversas experiencias populares del tiempo. En contraste con toda estandarización, las claves presentan un conflicto permanente entre sus elementos que ni siquiera pretende resolverse, del mismo modo que la sociedad transcultural que estas músicas habitan asume "la condición transitoria de la mezcla» (Podetti, 2004, p. 4).

Sobre la clave básica que transcribimos más arriba se despliega en «La Perla» la voz principal de René Pérez, que en la primera mitad de la canción se organiza de acuerdo al rapeo y mantiene la entonación en torno a dos alturas poco determinadas. El ritmo de este recitar es un floreo o repiqueteo constante sobre el toque (el despliegue de la clave) que asumen los tambores. Naturaleza dialógica de estas músicas, que se organizan en 
torno a la alternancia entre tamboreros, cantantes y bailadores. Pero lejos de ser los que floreon el centro de la música y subordinar al resto, en las músicas afrodescendientes latinoamericanas, desde el Sur hasta el Caribe, es el toque la figura central que mantiene la tensión y el interés en la repetición. Dentro de los tambores existen, además, funciones, y mientras unos llevan el ritmo básico de la clave otros repican sobre aquél. Roles que habitualmente se denominan bomba o buleador y primo o subidor, que se asocian con lo femenino y lo masculino, de tal forma que la figura principal que subordina al resto es lo femenino. Este plano de los tambores a su vez es el que manda mediante el desarrollo completo de la clave y en conflicto dialógico con él los bailadores, los instrumentos melódicos y el canto desarrollan sus descargas y voceos, mayormente improvisados.

A diferencia de lo que ocurre con la tradición europea, donde [...] los tambores fueron relegándose al papel de ocompañontes, en estas músicas afrocaribeñas, marcadas por la zanja en continuidad temporal que representó la trata esclavista, continuaron siendo fundamentales para la elaboroción musical. Ésta se genera sobre todo en el diálogo creativo entre bailador y tocador [...] entre el espacio y el tiempo. Los bailadores siguen el toque básico del buleador, mientras a nivel individual desarrollan variadísimos movimientos creativos en controversia improvisadora con el subidor. Es muy significativo culturalmente que en el tipo de sociedad donde emergió esta música, su ritual simbólico comunicativo sea que el colectivo manda y el individuo floreo (Quintero Rivera, 2009, p. 42).

¿Es necesario resaltar hasta qué punto los rasgos de las músicas mulatas nos recuerdan el carácter subjetivo adorniano y la tensión necesaria entre sujeto y objeto, individuo y colectivo para que nos decidamos a abandonar su estigmatización y dejar de tacharlas por inauténticas? Por si nos quedan dudas, «La Perla» todavía tiene más para ofrecernos. En el estribillo la tensión rítmica entre el toque, las melodías de los metales y el bajo, y el voceo del coro se magnifica [Figura 2].

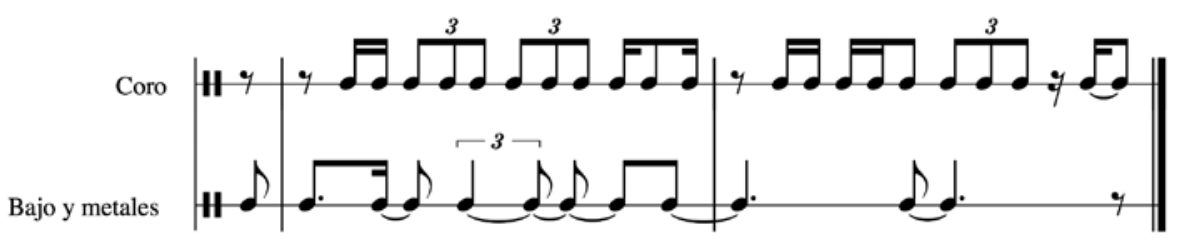

Figura 2. Transcripción del esquema rítmico del coro y del conjunto de metales y bajo eléctrico 
Este tipo de recurso en que los elementos individuales cambian su sentido constantemente a partir de su relocalización en torno a la clave se relaciona con otro principio rector importantísimo de las músicas afrodescendientes y que desafía tal vez con mayor contundencia la idea de estandarización: se trata de la intensificación por repetición.

Las músicas de tradición afroamericana se caracterizan por combinar simultáneamente, como la vida, la repetición y el cambio, en forma tal que las variociones tenues en lo repetido vayan intensificando un crescendo que conduzca a un clímax que represente una variación o cambio radical (Quintero Rivera, 2009, p. 86).

Exactamente hacia la mitad de "La Perla», concluido el segundo estribillo, los tambores quedan a solo con su clave plenamente configurada en su compleja trama de toque y repiqueteos. Sobre esta base aparece la voz del segundo cantante (Rubén Blades) que recita unas pocas frases y da pie a la segunda gran sección, que abandona el formato canción para pasar a una configuración típica de estas músicas: el soneo salsero, relación de llamada y respuesta entre el coro y un solista improvisador. Si tomamos la primera sección como un progresivo armado de la clave a partir de la aparición de los diferentes instrumentos, el enriquecimiento de la textura y el aumento paulatino de la intensidad, podemos escuchar que toda esa sección estructurada sobre la repetición permanentemente variada de la clave no hace otra cosa que conducirnos al clímax que es justamente el arranque del soneo. Éste, a su vez, insistirá aún más en la repetición del estribillo y su alternancia con las estrofas improvisadas, en las cuales el cantante gradualmente irá ampliando el rango de alturas, la densidad cronométrica y forzará el timbre de la voz para generar un potente aumento del dramatismo, que desemboca en una descarga, es decir, un solo de la trompeta, también improvisado y que explora el registro sobreagudo del instrumento. Tras un retorno breve al soneo y sin necesidad de cadencias ni otras redundancias, toda esta urdimbre tejida a lo largo de la canción finalmente se desarmará de manera fugaz.

No es posible vincular a esta música con ninguna clase de estandarización, simplemente porque la noción de desarrollo del material no existe. Y como esta ausencia es un rasgo de los más habituales en la música popular, y sobre todo en la afrodescendiente, podemos generalizar y adelantar que la repetición del material, mediante la intensificación según las tensiones de sus elementos internos, es un rasgo que no solo define a las músicas populares, sino que les permite exhibir rasgos disruptivos y divergentes. Si se quiere, como veremos, subversivos. Y sin necesidad de considerar el contenido de los textos, como el que Blades y Pérez cantan a lo largo de «La Perla», que intencionalmente no analizamos aquí. Mediante la organización mulata, transcultural de esta música, podemos escuchar en sus 
propios materiales, como banda audible, la crítica hacia la dominación de Panamá y Puerto Rico.

\section{ADORMECIMIENTO Y TRANSFERENCIA DE LA RESISTENCIA}

«Actuamos, en general, como si el pueblo fuera mudo, aunque hagamos todo lo posible para que no sea sordo.» Eduardo Galeano (1981)

Para Adorno, sin embargo, esta música está muy lejos de ser vehículo del descontento social o de expresión de resistencia. Por el contrario, la música popular constituiría la opresión per se, e incluso más, contendría el dispositivo que previene de la toma de conciencia sobre esa operación, el cual se basa en el engaño y en la relocalización del destinatario de la resistencia:

La desproporción entre la fortaleza de cualquier individuo y la estructura so-

cial concentrada que tiene que soportar destruye su resistencia, creándole al mismo tiempo una mala conciencia por su voluntad de resistir. [...]. Aquí, el rencor se vuelve drásticamente activo [...]. Nada es más desagradable que confesar la dependencia [...]. El odio del engaño es transferido a la amenaza de darse cuenta del engaño y uno defiende su propia actitud con pasión ya que ésta le permite ser estafado voluntariamente (Adorno, [1941] 2002, p. 194)

Más allá de que las músicas populares declaren una vocación de resistencia, su propia constitución sonora y el mecanismo de la industria cultural las convertiría inevitablemente en instrumentos de dominación. Esto sería posible gracias al ocultamiento de sus verdaderas intenciones - la estafalo que generaría un sentido vergonzante para el caso de quien advierta la ilusión y pretenda resistirla. En última instancia, el rencor generado por la experiencia de la estafa es transferido como resistencia hacia quienes pretenden revelar el funcionamiento del mecanismo. Es casi un crimen perfecto.

Para indagar en el funcionamiento de este presunto mecanismo de opresión tomaremos un caso que se erige abiertamente como expresión contestataria: el fandango, que actualmente se circunscribe al estado mexicano de Veracruz. Autores como Gonzalo Camacho Díaz (2011) o Antonio García de León Griego (2002) le confieren directamente un carácter de subversión al orden social. Si bien el fandango es conocido como una danza española, las hipótesis más firmes indican su origen novohispano, es decir, mexicano en tiempos del sometimiento colonial (Katz, 2001). Aun- 
que puede postularse en términos de dialogismo (Camacho Díaz, 2011) es producto de un proceso histórico de apropiación, estilización y ocultamiento que comparte, por desgracia, con otras muchas músicas latinoamericanas, todas ellas danzas, como la zarabanda o la chacona.

Más allá de la disputa un tanto positivista sobre el origen, lo importante es el carácter afrodescendiente del fandango como expresión musical popular, lo que con el tiempo pasó a conocerse como son jarocho. En este caso incluso cabría hablar de un particular sentido de mestizaje y mulatería: lo caribeño afroandaluz (García de León Griego, 2002).

Más que un tipo de música, el fandango «es un sistema de ocasiones musicales» (Camacho Díaz, 2011, p. 45) derivadas de los oratorios, espacios de reunión con función ritual cristiana generados a partir de que las autoridades virreinales delegaran en los primeros siglos de la colonia la observancia de la liturgia en las familias patricias, ante la escasez de iglesias y en virtud de la tarea evangelizadora propuesta por la corona. En estos lugares domésticos de reunión se daban cita las comunidades indígenas, los esclavos africanos, los españoles pobres, los ricos nobles o los hacendados, los comerciantes. Todos portadores de tradiciones diversas que, al derivar estas prácticas en la configuración de la religiosidad popular tan habitual en Latinoamérica, dan lugar a prácticas musicales y dancísticas de carácter mestizo y/o mulato: zarambeques, jarabes, zapateados, jaranas, sonecitos, villancicos, tocotines que se van configurando a partir de la heterogeneidad, siempre conflictiva, de multitud de danzas y cantos africanos, indígenas, andaluces o castellanos, provenientes de «todo género de gente [...] de distintas costumbres» (Camacho Díaz, 2011, p. 53).

Una vez prohibidos los oratorios y reencauzado el ritual en la Iglesia, el sistema de ocasiones permanecerá y se transformará en el emergente de la fiesta comunal subalterna: el fandango. Vinculado a la independencia, el sentido contrahegemónico del fandango se agudiza. Se puede ver, si se quiere, en las letras, prohibidas permanentemente por la institucionalidad colonial. Pero eso es la superficie. Hacer visible el cuerpo y colocarlo en el centro, poblarlo de manoseos, contoneos, gestos indecentes es, en cambio, parte del núcleo de la subversión que estos espacios proponen. Exhibir el cuerpo es un rasgo constitutivo de la cultura popular, procedimiento que permite suspender la escisión de la cultura legítima occidental entre mente y cuerpo, razón y emoción:

Entrar en comunión con la vida de la parte inferior del cuerpo, el vientre y los órganos genitales, y en consecuencia también con los actos como el coito, el embarazo, el alumbramiento, la absorción de alimentos y la satisfacción de las necesidades naturales (Bajtin, 2003, p. 25).

Pero estos bailes mestizos ocurren junto con las músicas. ¿Cómo eran? ¿Acaso pobladas de rencor promoverían la transferencia de la resistencia, 
como propone Adorno? Recordemos que para Adorno [1941] (2002) los caracteres de opresión y control de la música popular se encuentran en la propia manifestación musical, es decir, están inscriptas en sus materiales, ya que «sin esconderse provocarían resistencia» (p. 171), aunque no tan oculta como para ser imperceptible. Aquí es donde el autor lanza una de las afirmaciones más contundentes y controversiales: «el oyente debe obligarse a aceptar» (Adorno, [1941] 2002, p. 194). De allí la reorientación del rencor hacia quienes intentan advertir al oyente del engaño sellado en la materialidad de la música, y no hacia quienes provocan tal ilusión opresiva. Condición para que esto suceda es nuevamente la estandarización de la música popular, manifiesta en la predeterminación estructural, la intercambiabilidad de los materiales, la recurrencia métrica y la superficialidad de lo que para el autor son detalles: todos los aspectos vinculados a la performance, lo interpretativo, el timbre, los rodeos rítmicos, la improvisación. Para ser crítico, es decir, auténtica, la música debe establecer una relación dialéctica entre los elementos aislados y la estructura, evitando la afirmatividad, es decir, sin resolver nunca la contradicción entre los materiales. La música popular no hace esto, ya que

[...] el efecto principal de esta relación entre la estructura y el detalle es que el oyente tiende a mostrar reacciones más fuertes hacia la parte que hacia el todo. Su comprensión del todo no se encuentra en la experiencia vivida de esta pieza concreta de música que ha escuchado [...]. El todo está dado y aceptado de antemano, incluso antes de que empiece la experiencia efectiva de la música (Adorno, [1941] 2002, p. 164).

Esto neutralizaría nuestra descripción del fandango como subversión del orden social, ya que más que poner en crisis el orden opresivo colonial, canalizaría ese rencor hacia los sectores críticos de la sociedad. Esto haría difícil sostener el vínculo entre la emergencia del fandango y el proceso independista. Pero intentemos una descripción de sus materiales y una reconstrucción a partir de documentos históricos y de performances actuales.

Nuestro ejemplo será un sonecito del país prohibido por la inquisición y de constatable participación en el sistema del fandango: el "pon de xarabe» (Inquisición, 1779-1788), fechado al menos hacia fines del siglo XVIII. La versión que de él hace el guitarrista argentino Gabriel Schebor junto a la cantante Mercedes García Blesa (Schebor, 2015) basa su estructura en un esquema de rasgueo derivado del complejo rítmico del son jarocho: una clave en contratiempo sobre una pulsación ternaria.

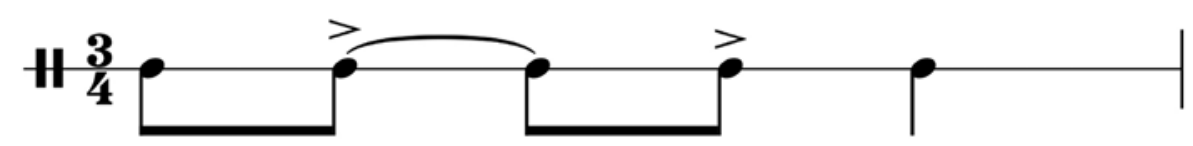

Figura 3. Clave sobre la cual se organiza el ritmo de «Pan de xarabe» 
Más allá de que la versión exhibe un carácter lírico muy marcado y en ocasión de concierto de cámara, el efecto de circularidad e inestabilidad permanente que genera este esquema rítmico en su relación con la melodía de la voz impide reunir ambos planos y estabilizarlos en una relación subordinada convencional. El rasguido del supuesto acompañomiento nos obliga a volver la atención hacia él constantemente, incluso cuando repite en toda la canción la misma secuencia armónica. Es un efecto similar al del joropo venezolano, la cueca chilena y tantas otras músicas populares latinoamericanas.

Pero el fandango no solo se actualiza en conciertos de música culta. La fiesta patronal de Santiago Apóstol en la ciudad de Santiago Tuxtla, por ejemplo, contiene entre sus actividades uno de los despliegues más conocidos del fandango. Si tomamos un registro entre tantos que se realizan año a año (Mozo, 2015) podremos advertir otras dimensiones que nos remiten muchísimo más a su carácter contrahegemónico. Para empezar, el instrumento principal, el más sonoro, es la tarima, sobre la cual se despliega el zapateo. Son únicamente mujeres las que bailan, en parejas, e instalan la presencia absoluta de los cuerpos. Este es el plano principal, pero no hay centro en esta música. Esto se advierte en el registro, en el cual la cámara debe transitar permanentemente entre las bailadoras, los músicos y todo aquel que esté participando en la ocasión. De hecho, el recinto, que se adivina una carpa, está hacinado de gente. Todos los que no bailan intervienen en la música, y aquí aparece el segundo plano, representado por jaranas de distintos registros y guitarras. Es imposible saber a ciencia cierta cuántos músicos son. Da la impresión de que cada quien concurrió con su instrumento y que, independientemente del número, todos tienen un lugar en la participación. Esta sensación se refuerza por el comportamiento de cada instrumentista que, si bien está integrado en el colectivo -que es el que mando-, actúa individualmente. Todos basan su performance en la clave que mencionamos antes, pero la alteran constantemente con ornamentaciones, subdivisiones y cuanto recurso de variación rítmico-tímbrica exista. A estos se les llama, curiosamente, tongueos. La armonía se mantiene siempre en una secuencia muy simple de dominante y tónica con alguna excursión breve a la subdominante. Pero ningún instrumento está afinado exactamente como los demás, por lo que el efecto tímbrico es increíblemente diverso. Sobre esta base, a su vez, se suceden en alternancia las figuros, punteos espontáneos e improvisados que hacen los instrumentistas, con las versadas, fragmentos cantados improvisados sobre un tema común a toda la ocasión del fandango. Los cantantes que se alternan también son muchos y hay tanto hombres como mujeres.

No puede sostenerse de ningún modo ante estas prácticas musicales aquello de que todo estó aceptodo de antemano. Aquí el sonido, la rugosidad de la diferencia de afinación, la rusticidad de los rasguidos que transforman los instrumentos de cuerda en percusión, los redobles sobre la 
tarima, no son detalles. Son materiales en tensión dialógica permanente, prácticas dialogantes entre lo cantado, lo textural, lo rítmico, lo bailado. Compartiendo rasgos con el resto de las músicas del mestizaje, podemos entender que en las ocasiones del fandango la elaboración musical no se basa, como en occidente, en una única dimensión: la armónica. La música tonal europea es la que responde a un esquema newtoniano integrado en relaciones infinitamente repetibles, funcionales y despersonalizadas, abstractas. En las músicas populares latinoamericanas, en cambio, la relación dialógica entre melodía, armonía y ritmo implica «una exploración entre las complejidades del ser y el convertirse. Y de aquí la importancia de la seducción en el baile [...] sin desenlace determinado» (Quintero Rivera, 2009, p. 84). Adorno hubiese querido decir de la música de vanguardia lo que Camacho (2011) describe del fandango:

De esa compleja diversidad emerge la unidad que supera las particularidades, que desdibuja la diferencia diluyendo las identidades previas [...] para después, como configuración inesperada, mixtura reciente, volver a diversificarse (p. 45).

Seguramente, alguien querrá impugnar nuestro caso del fandango argumentando que no se trata de música popular, sino de folklore. Si bien como vimos no queda claro si Adorno lo incluye o no en su análisis, queremos decir ahora y de una vez: el folklore no existe. A no ser como etiqueta comercial de un género musical, con autores e intérpretes profesionales y urbanos, sentido de seguro divergente al de la impugnación imaginaria. Interesante paradoja de nomenclaturas impuestas desde arriba al arte popular. Más allá de esto, el folklore no es sino una abstracción voluntariamente generalizante -lo ha sido desde la acuñación del término- de cierto tipo de arte popular en contro de otras manifestaciones, más vivas y diversas, de los sectores populares. Una operación que pone la historia en contra del pueblo. ${ }^{5}$ Es la creación de un nicho para lo que estaba fuera de la historia y transformarlo, así, en el expediente que refute la validez de la cultura popular contemporánea. Es el producto de las clases hegemónicas (Burke, 1991) en excursión ante aquello que no reconocen como propio y lo que históricamente -y hasta hace un rato nomás - ha sido despreciado por ellos mismos.

Más allá de estas consideraciones, el fandango es además urbano y desde los tiempos del oratorio fue practicado por profesionales, tanto músicos de la Iglesia como seculares, fuesen ellos españoles, indios, criollos o africanos. Todas las características asumidas por los románticos como indicadores de folklore (Burke, 1991) no las encontraremos aquí.

5 Johann Gottfried von Herder, fundador del folklore, nos ofrece precisiones sin ruborizarse: «el pueblo no es la turba de las calles, que nunca compone o canta, sólo chillan y destruyen» (Herder en Burke, 1991, p. 60). 
La pretendida comunalidad y anonimato no participan de ningún modo en el fandango. Tampoco existe aquí primitivismo alguno, ya que, como vimos, hay un continuo proceso de cambio y mutabilidad históricos. Lo cual nos lleva al tercer punto, tan caro a los folkloristas: el purismo. ¿Cómo sostener la búsqueda de lo no contominodo en las músicas populares latinoamericanas: mestizas, mulatas, transculturales? Como expresó con claridad simón Bolívar [1819] (1975), «es imposible asignar con propiedad a qué familia humana pertenecemos [...]. Nacidos todos del seno de una misma madre, nuestros padres difieren en origen y en sangre» (p. 226). Nuestras músicas expresan esa asunción.

\section{APOLOGÍA DE LA REPETICIÓN EN MÚSICA POPULAR}

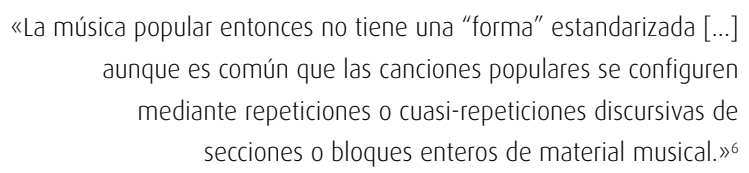

Alison Stone (2017)

Con la idea del tongueo propondremos un caso más para cotejar las hipótesis y despejar el equívoco entre estandarización y repetición: el tango «La yumba» (1946), de Osvaldo Pugliese. En él encontramos claramente un patrón de construcción por repetición. No sólo el acompañamiento está construido sobre un ostinato, sino, también, la figura instrumental que, al estar un tanto escondida entre la textura general, cuesta llamarle melodía. Tanto figura como fondo operan muy explícitamente, sin la necesidad de metáforas, como ese martilleo del que gustaba hablar Adorno. Las frases se estructuran en grupos de ocho compases que, a su vez, se subdividen en dos partes de cuatro y operan, incluso como antecedente y consecuente, en términos armónicos que, además, son escandalosamente simples: prácticamente un despliegue de dominante y tónica sobre la menor, esquema que luego se traspone secuencialmente, sin modular, al V grado. Bastaría decir esto para que nos convenzamos de estar en presencia de una de estas músicas que representan la estandarización opresiva, lo predecible, la ausencia de contradicción entre los materiales y la estructura. Sin embargo, algo se esconde por debajo - y por encima- de esta apariencia.

Por un lado, el interés del material principal no está en las notos. Esto es evidente en el cotejo de la partitura (una reducción al piano) con cualquiera de las versiones - para orquesta típica-

6 «Popular music, then, does not have a standard "form" [...] but it is standard for popular songs to be structured by discursive repetitions, i.e. repetitions or near-repetitions of entire blocks or sections of musical material» (Stone, 2017, p. 90). Traducción del autor del artículo. 
que se escuche. ${ }^{7}$ Tomando como referencia las del propio Pugliese, que sirven de modelo a las demás, se advierte que el material es antes que nada rítmico y tímbrico; esto último resulta de la combinatoria textural y de la aplicación de numerosos recursos de acción instrumental. Como sabemos esto es una marca identitaria de Pugliese, a quien, entre otras cosas, se le atribuye justamente el golpe yumbo del contrabajo, que consiste en golpear el fondo de la caja al mismo tiempo que se rebota el arco contra las cuerdas, efecto conocido en el ambiente del tango como strapato. Pero hay más. Los clusters en el extremo grave del piano, los ataques incisivos y golpeados hasta la exageración de las cuerdas y de los bandoneones: toda la orquesta suena al borde del estallido, como si los instrumentos y las manos de quienes los tocan fueran a romperse, a cortarse. La yumba mueve a los bailarines a danzar de acuerdo al timbre. En realidad, hay que hablar mejor del sonido, pues justamente plantea una ruptura con la idea de estandarización.

En momentos en que estaba haciendo crisis la producción en masa estondorizada del capitalismo fordista [...] el movimiento de esa sonoridad mulata que predominaría en las décadas siguientes, se inicia resaltando el valor de la heterogeneidad: cada orquesta debía poderse distinguir por su «sonido» propio (Quintero Rivera, 2009, p. 102).

El entramado textural y sonoro de «La yumba» revela que la composición basada en la repetición funciona como esquema, como excusa para la intersubjetividad de la orquesta, la performatividad y el ritual del tocar en vivo. En este sentido, lo de Pugliese es y no es composición, salvo que entendamos este término en sentido dialógico y no determinante de estructuras. ${ }^{8}$ Pero todavía hay algo de "La yumba» que podemos rastrear en la concepción del material y que también señala la elusión del tango a la estandarización: el ritmo, que justamente es el elemento que mejor revela el carácter mulato del tango. Aquí también el material de la pieza está concebido a partir de una clave. En este caso la misma no parece ofrecer demasiadas contradicciones internas, aunque por momento se vuelven más notorias [Figura 4]:

7 Puede escucharse aquí una versión de estudio por la orquesta del propio Pugliese https://youtu.be/V6LINj8X4NQ (Oeste Tango, 2011) y cotejarse además con esta otra, junto a Astor Piazzola https://youtu.be/46xiaNP8LE4 (Tango City Tour, 2013), en la cual se puede ver a un don Osvaldo visiblemente sorprendido ante la improvisación -un tanto adorniano- que ensaya Gerardo Gandini al piano a partir del minuto 3:25. ¿Habrá querido desestondorizor la Yumba el eximio compositor?

8 Sobre la superposición de los conceptos de forma, obra y composición puede consultarse María Paula Cannova y Martín Eckmeyer «Historia de la música y morfología musical. Algo más que una cuestión de formas» (2016). Para la filiación de origen de los conceptos de obra, compositor y partitura como núcleo duro de la musicología positivista, puede consultarse Martín Eckmeyer «Entre la música de las esferas y la sordera del genio. Sobre las persistencias del modelo historiográfico dominante en Historia de la Música» (2014). 


\section{A Y U M B A}

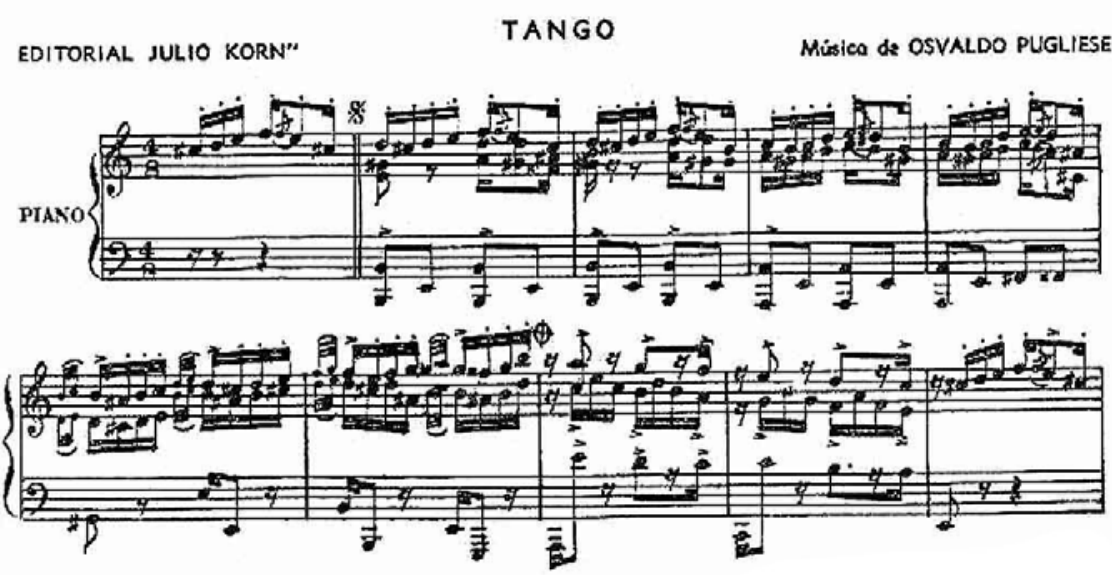

Figura 4. Fragmento inicial de «La Yumba» en versión para piano. Tango de Osvaldo Pugliese de 1964, publicado por la editorial Julio Korn

Sin embargo, el movimiento acéfalo, la insistencia del acompañamiento en acentuar todos los tiempos - que redunda en estatismo y licúa la percepción del compás- junto con el contorno que genera la ubicación de las alturas, produce la sensación de un desvío permanente, que sin embargo no puede nunca constituirse como norma. El metro nunca subordina ni absorbe al ritmo: están en contradicción y de ese roce constante emerge la atención y el interés de «La yumba». Eso es precisamente la clave. Un ritmo que está en las antípodas de la concepción unívoca y lineal occidental, del progreso tan caro a Adorno. Lo cual es en Latinoamérica una experiencia inevitable dada la heterología de concepciones y realidades sociales. Aunque trágica, nuestra realidad histórica y musical suena por todos lados la contradicción que buscaba Adorno en la música de vanguardia.

Adorno [1941] (2002) acusa también a la música popular de «intercambiabilidad» (p. 165) en el sentido de que las secuencias armónicas, los motivos melódicos y las estructuras formales, al estar predeterminadas por la industria cultural, son reemplazables por cualquier otra sin que se comprometa la función de la música. A tal punto son constitutivos los rasgos interpretativos, rítmicos y sonoros de «La yumba» que representan una impugnación fáctica de esa premisa: ninguno de los ataques del piano, los bandoneones o las cuerdas son iguales, desafiando la repetición mecánica que aparenta desplegar la pieza. Y esta halla su identidad a tal grado en el sonido y la contradicción rítmica que ningún elemento es reemplazable ni se puede omitir sin anular el efecto total de la música. Los detalles, si es que vamos a seguir llamándolos así, son aquí justamente los que constituyen la estructura. 
Jaques Attali (2011) también aborda la intercambiabilidad, y lo mismo hace Christopher Small (1989). Pero ambos, aún con sentidos diferentes, la ubican como constitutiva de la música culta tonal, la del eje vienés que tanto celebraba Adorno. La base de las ideas de ambos autores se encuentra en el principio básico de la música tonal, la funcionalidad. Aquí sí todo es sustituible: los sonidos, los timbres, incluso las mismas notas en sentido absoluto. Todas son funciones de otra cosa, valores lógicos que habitan las variables de un sistema que representa la cumbre de la racionalización occidental del arte sonoro. Tanto Attali como Small equiparan esto con la producción serializada del mundo industrial moderno. Curiosa paradoja que, aún sin que suscribamos las ideas de estos autores, refuerza el develamiento del sesgo adorniano que ya mencionamos: la concepción musical centrada en la armonía, en función de la cual todos los demás parámetros se subordinan y adquieren sentido.

\title{
LA INCONCLUSIÓN DEL COMBATE ENTRE CARNAVAL Y CUARESMA
}

\author{
«Como imagen invertida de esta canalización política, \\ subterránea y hostigada, una música subversiva se ha mantenido \\ siempre; una música popular, instrumento de culto extático, \\ superación de la violencia no censurada: [...] \\ La música es el lugar de la subversión, trascendencia del cuerpo.» \\ Jaques Attali (2011)
}

Como vimos, para Adorno el problema de la música popular no es su mansa aceptación o que las masas se comporten como autómatas mediante el engaño del material carente de contradicciones. La música popular cumple su cometido cuando las personas se esfuerzon en aceptarla, trabajan para ser estafados, invierten en su propia opresión. Aquí Adorno [1941] (2002) anticipa lo que desarrollará junto con Horkheimer en Dialéctica del Iluminismo en torno a la figura del amusement:

[...] no nos podemos limitar a la mera afirmación de que la espontaneidad ha sido reemplazada por la aceptación ciega del material impuesto. Incluso la opinión de que hoy las personas reaccionan como insectos y están degenerando en meros centros de reflejos socialmente condicionados es una fachada [...] simplemente para que a uno le "guste» la música popular, no es en absoluto suficiente abandonarse mostrando conformidad pasiva. Para transformarse en un insecto, el hombre necesita la energía que posiblemente podría conseguir transformarlo en un hombre (p. 198).

Adorno alude a los jitterbugs, los bailarines de swing, mote que en su 
etimología contiene, como metáfora, la imagen de un insecto nervioso e inquieto. En la crítica a estos personajes aparecerá un rasgo inequívocamente hostil hacia la cultura popular: la negación del valor de la risa y el humor. Según el autor el jitterbug se burla de sí mismo con sus propias muecas y placer, como si con ello pretendiera expiar el «fraude que ha cometido contra sí mismo» (p. 197). El humor es síntoma de la misma inautenticidad que revela la música sobre la cual danza. Es la marca de su falta de compromiso.

Su mal gusto, su furia, su resistencia escondida, su poca sinceridad, su desprecio latente hacia sí mismo, todo ello es encubierto por el «humor» y es de esta manera neutralizado. [...]. En todo el entusiasmo sobre la música popular hay un elemento de falsedad (Adorno, [1941] 2002, p. 197).

Quintero Rivera (2009) prefiere en cambio pensar al elemento dancístico de las músicas latinoamericanas como resultado del trance y la posesión, actitudes derivadas de la raíz animista y ritual, luego secularizadas y mutadas en performance, ante las cuales la música proyecta una función identitaria que se reconoce diversa y heterogénea. Puede resultarnos un tanto extremo hablar de posesión. Pero lo que resulta muy claro es que aquí no hay nada falso o inauténtico.

Además está el tema del humor y la risa. En esto Adorno está tan cerca de los inventores del folklore, que podemos ver revelado su costado más romántico.

\footnotetext{
La concepción estrecha del carácter popular y del folklore, nacida en la época pre-romántica y rematada esencialmente por Herder y los románticos, excluye casi por completo la cultura específica de la plaza pública y también el humor popular en toda la riqueza de sus manifestaciones (Bajtín, 1974, p. 9).
}

Para compensar esto debemos considerar la tradición historiográfica social sobre la cultura popular, al punto de denominarla como cultura de la riso. Ésta se opone directamente a la cultura oficial, justamente al poner en crisis su tono serio. ${ }^{9}$ La sátira carnavalesca, el lenguaje grosero adrede, las máscaras y muecas, hacer coras, bailar desenfrenadamente; en eso reside precisamente el carácter contrahegemónico y de resistencia de la cultura popular. Manifestaciones deliberadamente no oficiales, alternativas, divergentes que "parecían haber construido, al lado del mundo oficial, un segundo mundo y una segunda vida» del pueblo (Bajtín, 1974, p. 11).

Ese segundo mundo está habitado por una enorme heterogeneidad, asistemática, desordenada, múltiple e incluso estratificada, ya que el pueblo nunca es una unidad homogénea, masa. Por esta razón su descripción 
homogeneizante en términos de dominación, de respuesta acrítica y cuasi robótica ante los productos culturales, es tan inadecuada como concebirlos intrínsecamente desafiantes y en contradicción frontal y permanente con la cultura legítima. Si se quiere, esto se relaciona con el esquema de las formaciones culturales desarrollado por Raymond Williams (2015) que caracteriza en términos de residual o emergente, accesibles ambas en términos de prácticas que ofrecen «una alternativa a la producción cultural contemporánea dominante» (p. 189). Entre estas dos formaciones deberíamos buscar el lugar de la música popular latinoamericana y su específica relación entre el propio pasado y la proyección divergente. Este esquema guarda cierta analogía con el pensamiento de Antonio Gramsci [1975] (2000), entre los estratos fosilizados, por momentos reaccionarios y conservadores, y los creativos y progresistos que están en contradicción, o solamente son distintos, de la moral de los estratos dirigentes. Hay que advertir, además, la existencia de estratos populares de aparente indiferencia ante las formas dominantes y que no por eso necesariamente expresan su aceptación total. Como nos recuerdan Claude Grignon y Jean-Claude Passeron (1992) además de la alternancia en contra del segmento dominante, en las culturas populares se da también la ambivalencia en virtud de la cual funcionan «en modo de descanso» (p. 108) y promueven lugares de alteridad, heteronomía y relativa autonomía. Puede hablarse, entonces, de subculturas, como hace Peter Burke (1991) en el sentido de un sistema de significados compartidos entre un grupo social, pero que no restringe a sus miembros de participar de significados procedentes de otros repertorios, incluso de la cultura dominante. En definitiva, «hay muchas culturas populares o muchas variedades de cultura popular, dos ideas entre las que es difícil elegir» (Burke, 1991, p. 86).

Sin embargo, esto no debe llevarnos al relativismo, que es justamente la coartada del autonomismo folklórico. Y si bien no hay homología de términos entre clase y cultura, pues como vimos no hay homogeneidad ni fijeza en las formaciones culturales, ambos términos están íntimamente relacionados. Podríamos pensar como hace Ticio Escobar (1991) que el término popular responde a una posición asimétrica de ciertos sectores muy plurales, un colectivo amplio pero atravesado por situaciones de opresión, explotación, marginación y discriminación. Una suerte de convergencia de sectores populares en relación dialéctica con la alianza de las fuerzas que conscientemente no son el pueblo: "El término "popular" indica esta relación un tanto desplazada entre la cultura y las clases» (Hall, 1984, p. 10).

Debemos sospechar, por tanto, de las definiciones homogéneas de pueblo y popular, ya que "podemos tener la seguridad de que también a otras fuerzas les interesa definir "el pueblo" como otra cosa: "el pueblo" [...] cuya forma de vida necesita que la protejan de "culturas extranjeras"» (Hall, 1984, p. 11). En Adorno lo extraño al pueblo es justamente la música popular, idea que revela un gesto cuanto menos paternalista. La homogeneización de la música popular es tal vez uno de los problemas más 
evidentes del análisis de Adorno sobre la música popular. Pensar que estas músicas se despliegan en una esfera cultural que no puede conectarse con la de la música culta de vanguardia sin depender una de otra (Adorno, [1938] 2009) y que quienes consumen lo popular lo hacen en tanto están segregados y desconectados de la cultura crítica es justamente reproducir la tesis de autonomización. Hacer de la música popular un gran conjunto único, envilecido y adormecedor, así como asumir que los sectores que la producen y consumen son tontos culturales es, de hecho, suscribir la definición que de popular hace el mercado.

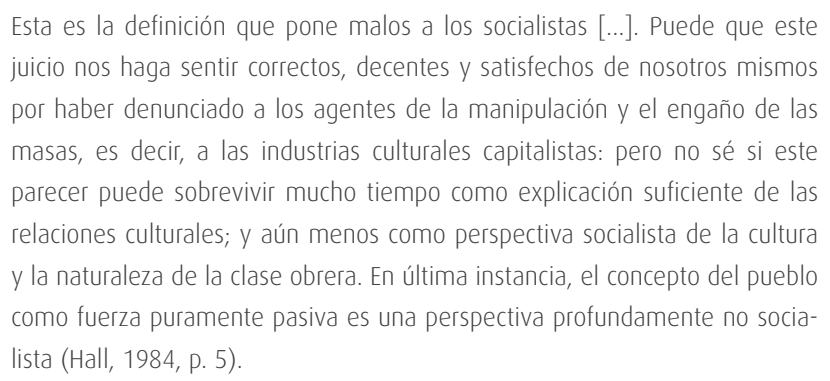

Habrá que buscar, entonces, el sentido de lo popular en las relaciones -de tensión y oposición, pero también de ambivalencia y aceptación-entre la multiplicidad inorgánica y desestructurada de los sectores oprimidos, y aquellos que encuentran en la distancia hacia el pueblo su identidad de élite dominante. El carnaval, como vimos, extrae sus materiales y produce su comicidad disruptiva sintetizando, también, lo que reconoce parte de la élite. La mueca del jitterbug, el trance de la danza, es también máscara grotesca que degrada los contenidos y materiales del arte legítimo y culto. «Por lo tanto, dicotomía cultural, pero también circularidad, influencia recíproca [...] entre cultura subalterna y cultura hegemónica» (Ginzburg, 1986, p. 15).

Esta circularidad entre lo culto y lo popular es la que expresan las músicas populares latinoamericanas que "emergen [...] a partir del dialogismo entre los ámbitos eclesiástico y civil, entre la oralidad y la escritura, entre lo hegemónico y lo subalterno» (Camacho Díaz, 2011, p. 47). Son parte de la cultura expresiva de los sectores subalternos caracterizada por la fiesta, el exceso y, sobre todo, la música y la danza, el baile. Aquí observamos un paradigma en el cual con claridad la cultura popular se visibiliza en los cuerpos en movimiento y su proyección subversiva: el éxtasis, el arrebato, el trance, el desorden. El cuerpo atravesado por este régimen de movimiento que trasuntan las músicas mulatas no es solamente la emergencia irrefrenable de lo sexual -lo cual no es poco- sino, también, la exposición del objeto en donde se hacen visibles la miseria, la enfermedad y la pobreza. El cuerpo recibe las marcas que le infligen la opresión y la desigualdad. Por 
eso la cultura legítima del orden racional del capitalismo colonial siempre buscó ocultar el cuerpo, someterlo, domesticarlo, estilizarlo. El danzante mundo afroamericano, en cambio, exhibe esas cicatrices en un conjuro que, lejos de querer borrarlas, evita sonoramente, musicalmente, que se las oculte y olvide.

\section{REFERENCIAS}

Adorno, T. W. [1932] (2015). Sobre la situación social de la música. En Escritos musicales V: Obro completo 18. Madrid, España: Akal.

Adorno, T. W. [1936] (2015). Sobre el Jazz. En Escritos musicales IV: Obro completo 17. Madrid, España: Akal.

Adorno, T. W. [1938] (2009). Sobre el carácter fetichista de la música y la regresión de la escucha. En Disonancios. Introducción a la sociología de la música (pp. 12-52). Madrid, España: Akal.

Adorno, T. W. [1941] (2002). Sobre la música popular. Guaroguao, 6(15), 163-201. Recuperado de http://www.jstor.org/stable/25596308

Attali, J. (2011). Ruidos: Ensayo sobre la economía política de la música. Ciudad de México, México: Siglo XXI.

Attali, J. (2001). Ruidos. Transcripción de la Conferencia presentada en el ICA (Institute of contemporary arts). Londres, Inglaterra. Recuperado de http://www.eumed.net/cursecon/textos/2005/attali-ruidos.htm

Bajtin, M. (2003). La cultura popular en la Edad Media y Renacimiento. Madrid, España: Alianza Editorial.

Bolívar, S. (1975). Discursos, proclamas y epistolario político. Madrid, España: Editora Nacional.

Burke, P. (1991). La cultura popular en la Europa moderna. Madrid, España: Alianza Editorial.

Calle 13; Blades, R. y La Chilinga. (2008). La Perla. En Los de atrás vengan conmigo [CD]. Trujillo Alto, Puerto Rico: Sony - BMG Music Entertainment. Camacho Díaz, G. (2011). Del oratorio al fandango: la subversión del orden social. En A. García de León Griego (Comp.), Las músicas que nos dieron patria. Músicas regionales en las luchas de independencia y revolución (pp. 43-62). Tierra Caliente, México: Ediciones del programa de desarrollo cultural de Tierra Caliente.

Cannova, M. P. y Eckmeyer, M. (2016). Historia de la música y morfología musical. Algo más que una cuestión de formas. Revisto Clong, 4(4), 47-54. Recuperado de http://papelcosido.fba.unlp.edu.ar/pdf/revistas/clang/ Clang-4.pdf

Casa, L. y Maza, S. (2018). Argentango. La industria, lo nuestro, el otro y la novedad. Clong (5), 159-161. Recuperado de http://papelcosido.fba.unlp. edu.ar/revistas/clang.html

Colombres, A. (2007). Sobre la cultura y el arte popular. Buenos Aires, Argentina: Ediciones del Sol. 
Darwin Mozo. (24 de febrero de 2015). Santiogo Tuxtla Veracruz - Fandango [Archivo de video]. Disponible en https://www.youtube.com/watch?$\mathrm{V}=$ pIVXMr3XW-k

Eckmeyer, M. (2014). Entre la música de las esferas y la sordera del genio. Sobre las persistencias del modelo historiográfico dominante en Historia de la Música. Ponencia presentada en las 6. Jornadas de Investigación en Disciplinas Artísticas y Proyectuales. Facultad de Bellas Artes de la Universidad Nacional de La Plata, La Plata, Argentina. Recuperado de https:// es.calameo.com/books/000658104a07dd49442d6

El vecindario Calle 13. (25 de octubre de 2009). La Perlo (Long Vesion) ft. Rubén Blades, La Chilingo [Archivo de video]. Disponible en https://www. youtube.com/watch?v=B0cVKmkYamU

Escobar, T. (1991). El mito del Arte y el mito del Pueblo. En J. Acha, A. Colombres y T. Escobar, Hacio una teoría americana del arte (pp. 85-183). Buenos Aires, Argentina: Ediciones del Sol.

Frith, S. (2006). La industria de la música. En S. Frith, W. Straw y J. Street (Eds.), La otra historia del rock: Aspectos clave del desarrollo de la música popular: Desde las nuevas tecnologías hasta la política y la globalización (pp. 53-85). Barcelona, España: Ediciones Robinbook.

Frith, S. (2014). Ritos de la interpretoción: Sobre el valor de la música popular. Buenos Aires, Argentina: Paidós.

Gabriel Schebor. (21 de noviembre de 2015). Gabriel Schebor - El pan del jarabe [Archivo de video]. Disponible en https://www.youtube.com/ watch?v=Qi9qQXqEXfo

Galeano, E. (1981). La revolución como revelación. Triunfo, XXXV (13), 60-64. García de León Griego, A. (2002). El mar de los deseos. El Caribe hispano musical. Historia y contrapunto. Ciudad de México, México: Siglo XXI.

Ginzburg, C. (1986). El queso y los gusanos: El cosmos según un molinero del siglo XVI. Madrid, España: Muchnik Editores.

Gramsci, A. [1975] (2000). Cuadernos de la córcel. Ciudad de México, México: Era.

Grignon, C. y Passeron, J. C. (1992). Lo culto y lo popular: Miserabilismo y populismo en sociología y en literatura. Barcelona, España: Ediciones de La Piqueta.

Hall, S. (1984). Notos sobre la desconstrucción de «lo popular». En R. Samuel (Ed.). Historio popular y teoría sociolisto (pp. 93-112). Barcelona, España: Crítica.

Horkheimer, M. y Adorno, T. W. [1944] (2001). Dialéctica de la Ilustración: Fragmentos de filosofía. Valladolid, España: Trotta.

Inquisición. (1779-1788). Descripciones y edictos sobre el fandango y el pan de xarabe y otros bailes. (vol. 1297, exp. 3, fs. 14-23). Archivo General de la Nación, México.

Katz, I. (2001). Fondango en The New Grove Dictionary of Music and Musicions. Nueva York, Estados Unidos: Oxford University Press.

Leach, E. E. (2015). Popular Music. En J. P. Harper-Scott y J. Samson (Eds.), 
An introduction to music studies (pp. 188-200). Cambridge, Reino Unido: Cambridge University Press.

Middleton, R. (1990). Studying popular music. Berkshire, Reino Unido: Open University Press.

Moore, A. F. (2008). Analyzing popular music. Cambridge, Reino Unido: Cambridge University Press.

Negus, K. (1997). Popular music in theory: An introduction. Lebanon, Estados Unidos: University Press of New England.

Oeste Tango. (28 de noviembre de 2011). Lo Yumbo Osvaldo Pugliese y su Orquesto Tongo [Archivo de video]. Disponible en https://youtu.be/ V6LINj8X4NQ

Paddison, M. (1982). The critique criticised: Adorno and popular music. Popular Music, 2, 201.

Podetti, R. (2004). Mestizaje y transculturación: la propuesta latinoamericona de globalización. Ponencia presentada en el $6 .^{\circ}$ Corredor de las Ideas del Cono Sur. Universidad de Montevideo, Montevideo, Uruguay.

Pugliese, O. (1946). Lo yumbo (tongo). Buenos Aires, Argentina: Editorial Julio Korn.

Quintero Rivera, A. (2009). Cuerpo y cultura: Las músicas «mulatos» y lo subversión del baile. Madrid, España: Iberoamericana.

Small, C. (1989). Música, sociedad, educación: Un examen de la función de la música en las culturas occidentales, orientales y africonas, que estudio su influencia sobre la sociedad y sus usos en la educación. Madrid, España: Alianza Editorial.

Stone, A. (2017). The Volue of Popular Music An Approach from Post-kontion Aesthetics. Basingstoke, Reino Unido: Palgrave Macmillan.

Tango City Tour. (26 de junio de 2013). Astor y Osvaldo en Ámsterdam [Archivo de video]. Disponible en https://youtu.be/46xiaNP8LE4

Williams, R. (2015). Sociología de la cultura. Barcelona, España: Paidós. 